\title{
Frequency of Hemorrhoidal Complaints in a Real-Life Population and Possible Concomitance between Hemorrhoidal Disease and Chronic Venous Disease: Going Further in Our Understanding of Hemorrhoidal Disease
}

\author{
Sheikh Firoj Kabir ${ }^{*}$, Debasish Das ${ }^{2}$, Kazi Zana Alam ${ }^{3}$, Mahbub Murshed ${ }^{4}$, Din Mohammad ${ }^{5}$ \\ ${ }^{1}$ Department of Surgery, US Bangla Medical College, Narayanganj, Bangladesh \\ ${ }^{2}$ Department of Surgery, Enam Medical College \& Hospital, Savar, Bangladesh \\ ${ }^{3}$ Department of Surgery, Sylhet M.A.G. Osmani Medical College \& Hospital, Sylhet, Bangladesh \\ ${ }^{4}$ Department of Surgery, Mainamoti Medical College \& Hospital, Cumilla, Bangladesh \\ ${ }^{5}$ Department of Surgery, Shaheed Suhrawardy Medical College and Hospital, Dhaka, Bangladesh \\ Email: ^drfiroj4562@gmail.com
}

How to cite this paper: Kabir, S.F., Das, D., Alam, K.Z., Murshed, M. and Mohammad, D. (2021) Frequency of Hemorrhoidal Complaints in a Real-Life Population and Possible Concomitance between Hemorrhoidal Disease and Chronic Venous Disease: Going Further in Our Understanding of Hemorrhoidal Disease. Surgical Science, $12,319-331$.

https://doi.org/10.4236/ss.2021.129033

Received: June 7, 2021

Accepted: September 15, 2021

Published: September 18, 2021

Copyright $\odot 2021$ by author(s) and Scientific Research Publishing Inc. This work is licensed under the Creative Commons Attribution International License (CC BY 4.0).

http://creativecommons.org/licenses/by/4.0/ cc) (i) Open Access

\begin{abstract}
Introduction: Hemorrhoids, more commonly known as piles, are swollen veins, similar to varicose veins in the lower rectum. Hemorrhoids can develop both inside and outside the rectum, and oftentimes, the cause of hemorrhoids remains unknown. This is an extremely common ailment faced by three out of four adults in their lifetime. Hemorrhoids can cause various kinds of complications, but the most common and serious ones are perianal thrombosis and incarcerated prolapsed internal hemorrhoids with subsequent thrombosis. They are accompanied by severe pain in the perianal region, and possible bleeding. Data on the coexistence of hemorrhoids with other conditions are sparse. Some data are consistent with a common pathophysiological link between straining at stool, constipation, and obstetrical events such as pregnancy and delivery. These events are also involved in the development of Chronic Vein Disease (CVD) or Chronic Vein Insufficiency (CVI). CVI is a condition that occurs when the venous walls or valves in the leg veins stop working properly, causing difficulty in blood returning to the heart from the legs. The present study was conducted with an aim to determine the frequency of complaints in hemorrhoidal patients and to assess the possible concomitance between hemorrhoidal disease and chronic venous disease. Methods: This was a multicenter, cross-sectional, observational study that enrolled patients spontaneously consulting for hemorrhoids in 17 different hospitals of
\end{abstract}


different regions of Bangladesh from $1^{\text {st }}$ June 2018 to $31^{\text {st }}$ July 2018. Patients' demographic and lifestyle characteristics were recorded, information on hemorrhoidal grade and signs of chronic venous disease was collected. Types of prescribed treatments were also recorded by the physicians. Results: A total of 499 patients were enrolled and analyzed. Reported frequencies of hemorrhoidal symptoms were: bleeding (80.8\%), pain (66.3\%), swelling (51.7\%), prolapse (28.9\%), itching (37.7\%), soiling (12\%), fecal incontinence (13.4\%). $13.8 \%$ of the hemorrhoidal patients presented concomitant chronic venous disease. The Clinical-Etiological-Anatomical-Pathophysiological (CEAP) classification was used to classify the clinical signs and symptoms of the patients as $\mathrm{C} 0$ - no visible or palpable signs of venous disease (6.2\%), C1-telangiectasias or reticular veins (4.4\%), C2-varicose veins (1.4\%), C3-edema (2.6\%), $\mathrm{C} 4 \mathrm{a}$ - pigmentation or eczema (2\%), C4b-lipodermatosclerosis or Atrophie Blanche (0.2\%), C5 \& C6-venous ulcer (0.6\%). Commonly prescribed treatments were dietary fiber $(89.8 \%)$, veno-active drugs $(74.7 \%)$, topical treatments (63.7\%), painkillers (11.2\%), and surgical procedures $(30.3 \%)$. Conclusion: The study provides small-scale data on patient profiles, risk factors, and commonly prescribed treatments in hemorrhoidal patients. The concomitance of chronic venous disease in $13.8 \%$ of the hemorrhoidal patients highlights the importance of examining for Chronic Venous Disease (CVD) with a hemorrhoidal diagnosis. Further clinical studies and large-scale data are needed to confirm the co-morbidity of these two diseases and a common targeted treatment should be developed thereby. Since even early symptoms greatly affect the lives of hemorrhoidal patients, a conservative treatment appears to be the cornerstone treatment in disease management.

\section{Keywords}

Hemorrhoidal Complaints, Chronic Venous Disease, Frequency

\section{Introduction}

Hemorrhoidal disease is considered to be one of the most common anorectal pathological conditions worldwide. Though symptomatic hemorrhoidal disease significantly hampers the quality of life, in most cases, patients are disinclined to seek medical attention. This makes it difficult to determine the exact incidence of the condition. Hemorrhoid disease is said to be the fourth leading outpatient gastrointestinal diagnosis, accounting for 3.3 million ambulatory care visits in the United States [1]. Although so common, only around 4\% seek medical help [2]. Levels of spontaneous consultation for hemorrhoidal symptoms worldwide are only around $2 \%$, increasing to around $14 \%$ when patients presenting for an unrelated condition are subject to targeted questioning [3] [4]. The most common complaints related to hemorrhoids are bleeding, pain during defecation, swelling, prolapse, itching and fecal incontinence.

The exact pathophysiology of hemorrhoidal disease is still not completely un- 
derstood. Several mechanisms may be involved including sliding anal cushion, hyperperfusion of hemorrhoidal plexus, vascular abnormality, tissue inflammation, and internal rectal prolapse. Factors like constipation, straining during defecation, pregnancy, obesity aggravate the above-mentioned pathologic changes. These factors are also involved in chronic venous disease development. The co-morbidity of these two disease conditions is yet to be properly evaluated.

The different philosophies of hemorrhoidal disease development may lead to different approaches to the treatment of hemorrhoids [5]. Dietary and lifestyle modifications remain the primary choice of physicians for hemorrhoidal disease management. Other treatments include pharmacological approach, hemorrhoidectomy, and other non-excisional surgeries.

In light of these data, this study aimed to determine the frequency of complaints such as pain, bleeding, rectal swelling, itching, soiling, as well as constipation in subjects consulting for hemorrhoids and to assess the possible concomitance between hemorrhoids and chronic venous disorders.

\section{Methods}

This was a multi-center, cross-sectional, observational study. The study was conducted by 20 Physicians involved in hemorrhoidal disease management from 17 hospitals located in different regions of Bangladesh. The study period lasted for 2 months, from $1^{\text {st }}$ June 2018 to $31^{\text {st }}$ July 2018. Convenient sampling technique was used for selection of the study sample. After obtaining informed consent, 499 Patients aged over 18 years and consulting spontaneously for hemorrhoidal complaints or referred by another physician for hemorrhoids were enrolled. Patients who were consulting for other emergencies except hemorrhoids were excluded from the program. Informed written consent was taken from all the participants. Ethical approval was taken from the Department of Surgery, US Bangla Medical College, Narayanganj, Bangladesh.

Demographic data and lifestyle characteristics of the subjects were collected including age, sex, body mass index, occupationally activeness, duration of standing position in a day, smoking habits, and obstetrical history. Subjects were asked to describe their anal complaints including symptoms, presence or duration of constipation, duration of evacuation, use of laxatives, consistency of stools in the last 15 days using the Bristol stool scale, [6] history of hemorrhoids. Patient examination, if performed, was described (digital and/or anoscopy) and the type (internal, external or mixed) and grade of hemorrhoids were noted. Internal hemorrhoids were graded from I to IV according to the classification of Goligher et al. [7] Patients were also questioned about the chronic venous disease of the lower extremities and chronic venous disease was graded according to the revised CEAP (Clinical manifestations, Etiologic factors, Anatomic distribution of disease, and underlying Pathophysiology) classification [8]. Details of any hemorrhoidal treatment prescribed including dietary fiber, topical treatment, veno-active drugs, pain killers, and surgery (including minimally-invasive 
procedures) were recorded. All necessary information was collected through a detailed questionnaire and test results of participants, and the collected data was compiled and analyzed using SPSS software.

\section{Results}

The study included 499 patients with hemorrhoids who met the selection criteria. The mean age was $38.6 \pm 11.4$ years (range 15 - 83 years) and the male:female ratio was 1.6:1 [Table 1]. BMI was normal for most of the participants [Table 2]. $71.5 \%$ of the participants were occupationally active [Table 3]. Duration of standing position during the day was less than 2 hours for $46.7 \%$ of the participants [Table 4]. Most of the participants (60.5\%) were nonsmokers [Table 5]. Most of the participants (87.4\%) had given birth before [Table 6]. Less than 18 months of constipation was recorded for most of the participants [Table 7]. $32.1 \%$ were laxative medication users [Table 8]. $67.1 \%$ of participants had evacuation lengths of 6 to 30 minutes [Table 9]. Consistency of stools in the last 15 days (without laxatives) were type 3 in $23.8 \%$ of participants [Table 10]. History of hemorrhoids was present in $68.1 \%$ and among them, history of hemorrhoids once was present in $43.8 \%$ [Table 11]. $92.4 \%$ were examined. Among them, $38.9 \%$ were digitally examined [Table 12]. Grade 2 hemorrhoids were present in the maximum (37\%) number of the participants after examination [Table 13]. The most frequently encountered complaints were bleeding (80.8\%), pain (66.3\%), swelling (51.7\%), prolapse (28.9\%), itching (37.7\%), soiling (12\%) and fecal incontinence (13.4\%) [Figure 1]. Among the hemorrhoidal patients, $13.8 \%$ presented concomitant chronic venous disease. CEAP classification was used to classify the clinical signs and symptoms of the patients as C0 (6.2\%), C1 (4.4\%), C2 (1.4\%), C3 (2.6\%), C4a (2\%), C4b (0.2\%) and C5 - C6 (0.6\%) [Figure 2]. Maximum patients $(89.8 \%)$ were prescribed Dietary fiber. Topical treatment,

Table 1. Age distribution of the study respondents.

\begin{tabular}{|c|c|c|}
\hline Age group (in years) & Frequency & Percentage (\%) \\
\hline$<20$ & 9 & 1.8 \\
\hline $21-30$ & 130 & 26.1 \\
\hline $31-40$ & 186 & 37.3 \\
\hline $41-50$ & 104 & 20.8 \\
\hline $51-60$ & 46 & 9.2 \\
\hline $61-70$ & 21 & 4.2 \\
\hline$>70$ & 3 & 0.6 \\
\hline Mean \pm SD & \multicolumn{2}{|c|}{$38.6 \pm 11.4$} \\
\hline \multicolumn{3}{|c|}{ Sex } \\
\hline Male & 308 & 61.7 \\
\hline Female & 191 & 38.3 \\
\hline Male:Female ratio & \multicolumn{2}{|c|}{$1.6: 1$} \\
\hline
\end{tabular}


Table 2. Distribution of the study respondents by BMI.

\begin{tabular}{ccc}
\hline BMI $\left(\mathrm{kg} / \mathrm{m}^{2}\right)$ & Frequency & Percentage (\%) \\
\hline Underweight $(<18.5)$ & 24 & 4.8 \\
Normal $(18.5-24.9)$ & 259 & 51.9 \\
Overweight $(25.0-29.9)$ & 147 & 29.5 \\
Obese $(>30.0)$ & 69 & 13.8 \\
\hline
\end{tabular}

Table 3. Distribution of the study respondents by occupationally activeness.

\begin{tabular}{ccc}
\hline Occupationally activeness & Frequency & Percentage (\%) \\
\hline Yes & 357 & 71.5 \\
No & 142 & 28.5 \\
\hline
\end{tabular}

Table 4. Distribution of the study respondents by duration of standing position during in a day.

\begin{tabular}{ccc}
\hline Duration (hours) & Frequency & Percentage (\%) \\
\hline 2 hours or less & 233 & 46.7 \\
Between 3 and 6 hours & 201 & 40.3 \\
7 hours or more & 65 & 13.0 \\
\hline
\end{tabular}

Table 5. Distribution of the study respondents by smoking status.

\begin{tabular}{ccc}
\hline Smoking status & Frequency & Percentage (\%) \\
\hline Never & 302 & 60.5 \\
Now & 132 & 26.5 \\
Quit & 65 & 13.0 \\
\hline
\end{tabular}

Table 6. Distribution of the study respondents by obstetrical history.

\begin{tabular}{ccc}
\hline Obstetrical history & Frequency & Percentage (\%) \\
\hline Use birth control pills & 97 & 50.8 \\
Use estrogen replacement therapy & 28 & 14.7 \\
Birth given & 167 & 87.4 \\
Number of births & & \\
One & 42 & 22.0 \\
Two & 45 & 23.6 \\
Three & 39 & 20.4 \\
Four & 17 & 8.9 \\
Five & 7 & 3.7 \\
\hline
\end{tabular}

Table 7. Distribution of the study respondents by constipation.

\begin{tabular}{ccc}
\hline Constipation & Frequency & Percentage (\%) \\
\hline Not constipated & 112 & 22.4 \\
Less than 18 months & 229 & 45.9 \\
More than 5 years & 70 & 14.0 \\
Not known & 88 & 17.6 \\
\hline
\end{tabular}


Table 8. Distribution of the study respondents by regular use of laxatives.

\begin{tabular}{ccc}
\hline Regular of laxatives & Frequency & Percentage (\%) \\
\hline Yes & 160 & 32.1 \\
No & 339 & 67.9 \\
\hline
\end{tabular}

Table 9. Distribution of the study respondents based on the evacuation.

\begin{tabular}{ccc}
\hline Duration of evacuation & Frequency & Percentage (\%) \\
\hline Less than 5 minutes & 139 & 27.9 \\
6 to 30 minutes & 335 & 67.1 \\
More than 30 minutes & 25 & 5.0 \\
\hline
\end{tabular}

Table 10. Distribution of the study respondents by consistency of stools in the last 15 days (without laxatives).

\begin{tabular}{ccc}
\hline Consistency of stools & Frequency & Percentage (\%) \\
\hline Type 1 & 50 & 10.0 \\
Type-2 & 89 & 17.8 \\
Type 3 & 119 & 23.8 \\
Type 4 & 102 & 20.4 \\
Type 5 & 22 & 4.4 \\
Type 6 & 11 & 2.2 \\
Type 7 & 5 & 1.0 \\
Missing & 101 & 20.2 \\
\hline
\end{tabular}

Table 11. Distribution of the study respondents by history of hemorrhoids.

\begin{tabular}{ccc}
\hline History of hemorrhoids & Frequency & Percentage (\%) \\
\hline Yes & 340 & 68.1 \\
No & 159 & 31.9 \\
If yes, how many times in the last 2 yrs. & 149 & \\
Once & 119 & 43.8 \\
Twice & 62 & 35.0 \\
Between 3 and 5 times & 10 & 18.2 \\
6 times or more & & 2.9 \\
\hline
\end{tabular}

Table 12. Distribution of the study respondents by examination.

\begin{tabular}{ccc}
\hline Patients examination & Frequency & Percentage (\%) \\
\hline Yes & 470 & 94.2 \\
No & 29 & \\
If examined- & & 39.8 \\
Digital examination & 187 & 24.3 \\
Anoscopic examination & 114 & 36.0 \\
Both & 169 & \\
\hline
\end{tabular}


Table 13. Distribution of the study respondents by after examination grade of hemorrhoids.

\begin{tabular}{ccc}
\hline Patients examination & Frequency & Percentage (\%) \\
\hline Yes & 459 & 92.0 \\
No & 40 & 8.0 \\
If yes, the grade of hemorrhoids & & \\
Grade I & 122 & 26.6 \\
Grade II & 170 & 37.0 \\
Grade III & 128 & 27.9 \\
Grade IV & 39 & 8.5 \\
\hline
\end{tabular}

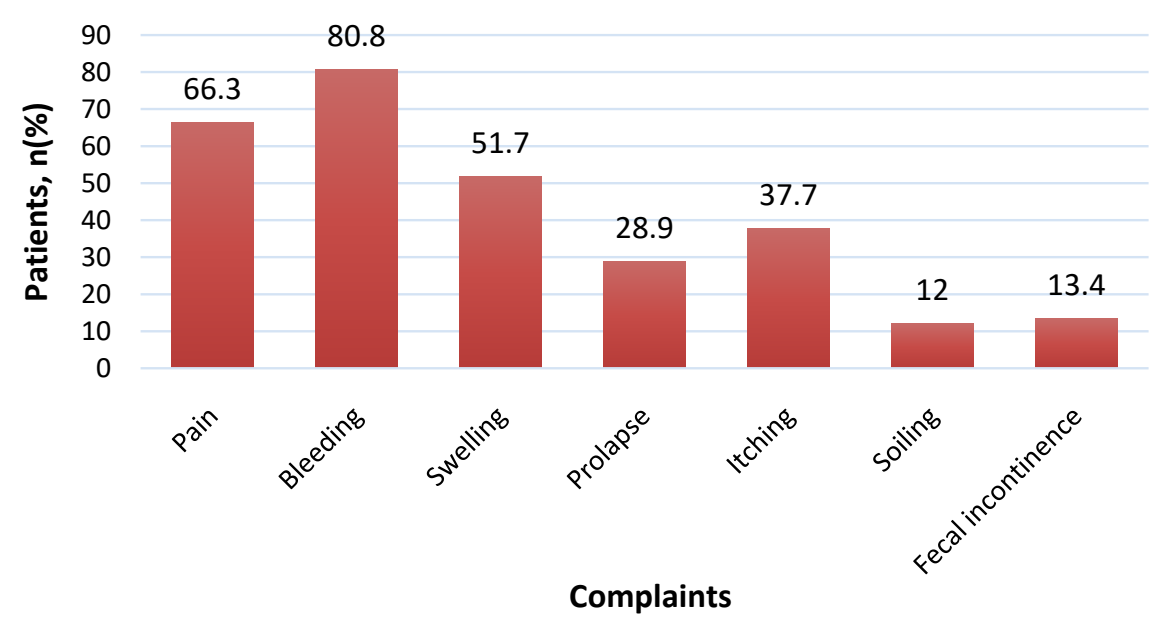

Figure 1. Frequency of hemorrhoidal complaints.

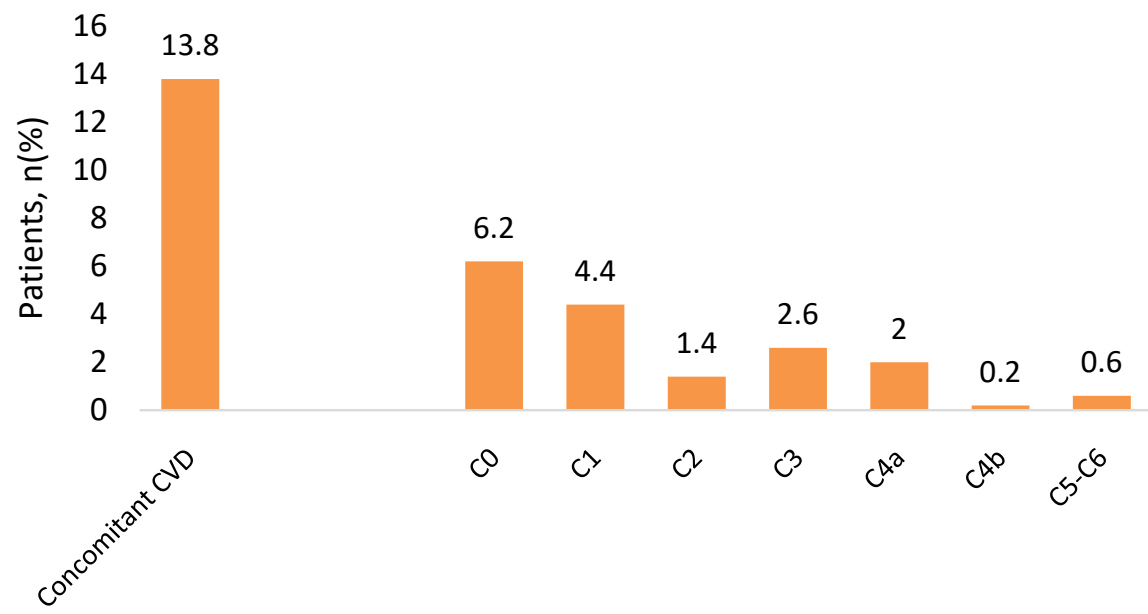

Figure 2. Hemorrhoidal disease and chronic venous disease concomitance.

veno-active drugs, analgesics were prescribed as conventional treatments in respectively $63.7 \%, 74.7 \%$, and $11.2 \%$ of the patients. $30.3 \%$ of the patients underwent surgical procedures [Figure 3]. MPFF was the most prescribed veno-active drug (87.1\%). $12.3 \%$ and $0.7 \%$ of the patients were prescribed Diosmin and Calcium Dobesilate respectively [Figure 4]. 73.4\% of patients continued veno-active 
drugs for more than 4 weeks. $17.4 \%$ and $9.2 \%$ continued for 2 - 3 weeks and less than 1 week, respectively [Figure 5].

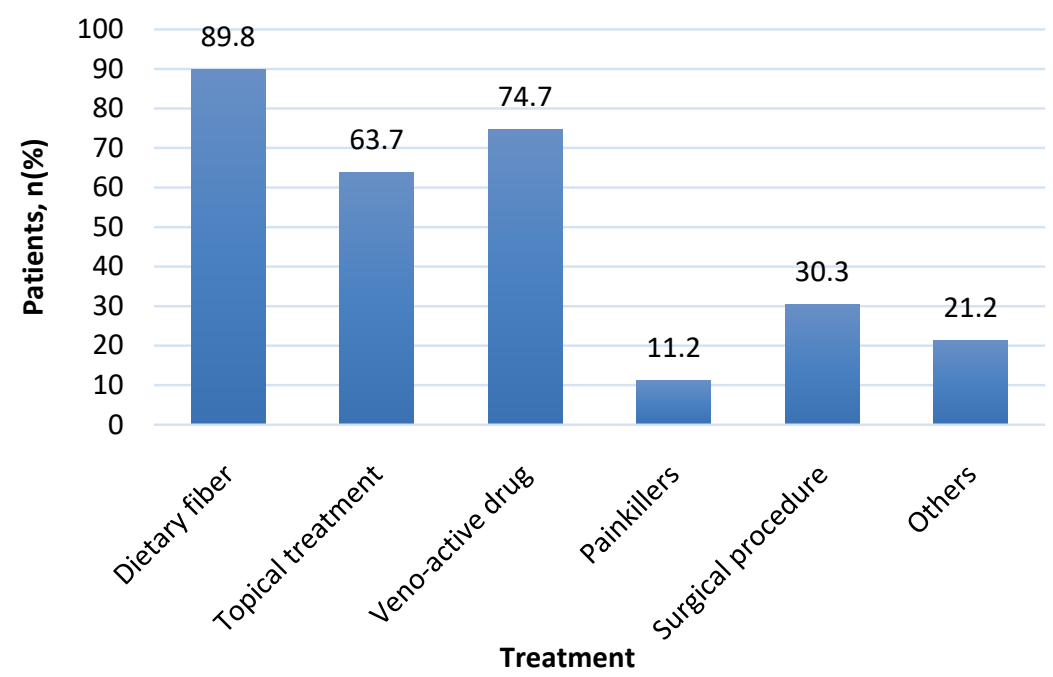

Figure 3. Types of treatment.

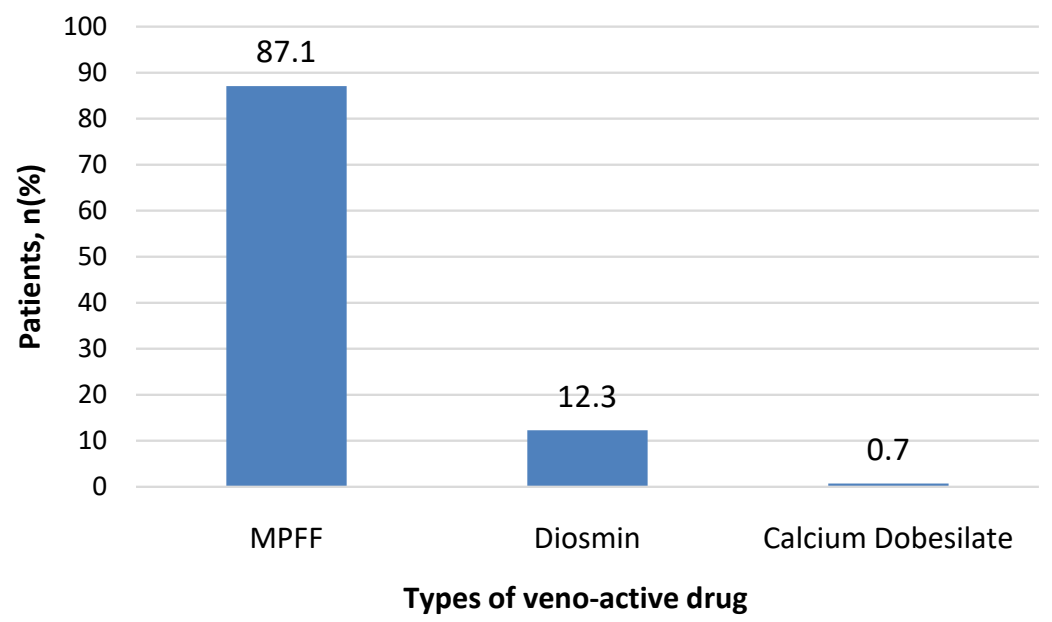

Figure 4. Distribution of study respondents by veno-active drug prescribed.

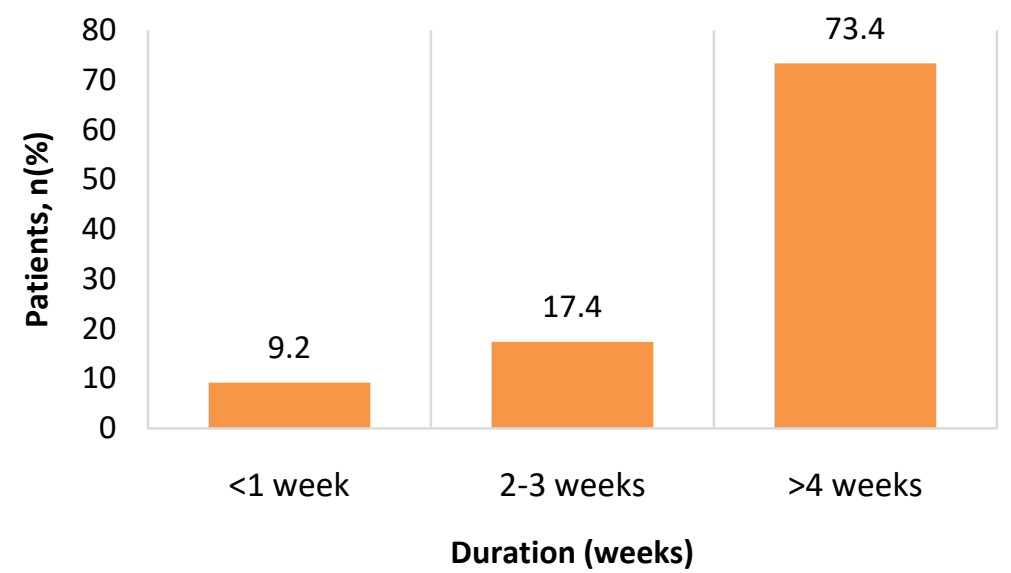

Figure 5. Duration of treatment with veno-active drug. 


\section{Discussion}

Almost all the participants (94.2\%) underwent a clinical examination, either digital and/or anoscopic. Although a digital examination cannot always confirm a diagnosis of lower grade HD, it is important to eliminate any local malignancies. Anoscopy is necessary for the diagnosis of Grade I hemorrhoids and was performed in most patients with low-grade hemorrhoids, thus confirming the high level of diagnostic evidence in this study.

Patients from the age group of 31 - 40 years were most in numbers to consult for hemorrhoidal problems. Male predominance was found among the patients (61.7\% vs. $38.3 \%$ ). This may reflect the cultural habits of people living in Bangladesh making women with HD reluctant to come forward.

$87.4 \%$ of the female patients had had at least one full-term pregnancy, and pregnancy is recognized as a risk factor for all grades of hemorrhoids. Hemorrhoids are common during pregnancy, particularly the last trimester, [9] [10] and although they generally resolve after delivery these women are at greater risk of hemorrhoids later in life. $29.5 \%$ of the patients were in the overweight category. and $13.8 \%$ were in the obese category. Some previous studies have hypothesized that obesity may be a risk factor for HD because of increased intraabdominal pressure and increased stress on rectal muscles [11].

Several studies in the past, including those that have used colonoscopy to confirm hemorrhoids, have shown an increased risk in patients with chronic constipation [12] [13] [14]. Whether causal or a contributory factor in the presence of a primary cause, prolonged straining increases intra-abdominal pressure and raises venous pressure in the hemorrhoidal tissue. In this study, more than half of the subjects (59.9\%) were suffering from constipation according to the Bristol stool scale and $67.1 \%$ reported a straining duration of 6 - 30 minutes.

Hemorrhoid recurrence rates have been reported to range from $4 \%-30 \%$ after treatment [15]. In this study, $68.1 \%$ of patients had had hemorrhoidal attacks previously.

Grade II hemorrhoids were found to be the most common (37\%) hemorrhoidal grade among the patients in this study followed by grade III (27.9) and grade I (26.6\%) hemorrhoids. This may be because patients are often ignorant of painless bleeding or are reluctant to consult with physicians unless the symptoms are severely hampering their day-to-day lives. Bleeding $(80.8 \%)$ followed by pain $(66.3 \%)$ and swelling $(51.7 \%)$ were the most common complaints presented.

Hemorrhoidal disease and chronic venous disease may have a common cause in the form of loss of vascular integrity, [16] though there are few published papers on the coexistence of these two disorders [17]. An early review of epidemiologic evidence for a link between HD and CVD hypothesized that chronic constipation associated with a low fiber diet was involved in both these diseases by increasing intra-abdominal pressure [17]. It was suggested that this pressure would easily be transmitted to the hemorrhoidal plexus, which has no valves. 
The valves of the lower limb veins would offer initial protection, but would eventually become incompetent and expose the veins to elevated pressure [17]. This hypothesis is supported by data from a Hungarian epidemiologic study of pregnant women, which found that around half with a diagnosis of HD also had constipation. Varicose veins were also more common in pregnant women with hemorrhoids compared with those without [18]. 13.8\% of this study subjects also presented with signs and/or symptoms of CVD, the majority having a CEAP classification of $\mathrm{COs}$ to $\mathrm{C} 1$. The finding should prompt physicians treating patients with a hemorrhoid diagnosis to also ask about CVD and vice versa.

Non-surgical approaches are preferred for lower-grade hemorrhoids because of the physiologic importance of the hemorrhoid cushions and the potential self-limiting nature of many hemorrhoidal symptoms [10] [15] [19] [20]. When conservative therapy fails, clinical practice guidelines recommend office-based procedures such as banding, sclerotherapy, and infrared coagulation for Grade I to III hemorrhoids [19] [21]. Surgical options such as hemorrhoidectomy, stapled hemorrhoidopexy, or hemorrhoidal artery ligation may be the initial step in patients with Grade III or IV hemorrhoids or in those who are refractory to or cannot tolerate office procedures [19] [21]. However, conservative therapy can still play a role, creating favorable conditions for a smooth post-operative recovery [22]. Adherence to these guideline recommendations is important to avoid repetitive and prolonged treatment and severe complications in Grade IV disease. The majority of the patients in this study received treatment with a veno-active drug, predominantly MPFF. MPFF is an effective treatment for acute hemorrhoidal attacks, and it has been shown to serve as an effective adjuvant to surgery or other procedures in the management of hemorrhoidal diseases [23]. MPFF is able to address the underlying causes of both symptomatic hemorrhoids and CVD via their beneficial effects on venous tone, inflammatory processes, and microcirculatory permeability [24]. Early use of such agents may play a role in preventing or slowing the development and recurrence of both hemorrhoidal and CVD signs and symptoms [25] [26].

\section{Limitations of the Study}

This study was conducted in multiple centers, and under different physicians, but the communication between the physicians was not strong. The study sample was also small compared to original goal. The sensitivity of the study topic also posed a limitation on how much data was able to be collected.

\section{Conclusion}

This study provided small-scale data on the profiles of patients presenting with HD in clinical practice. Factors like older age, obesity, constipation, increased evacuation time, male gender, and pregnancy were identified as having a statistically significant association with hemorrhoidal disease. Further studies are needed to confirm the co-relation between HD and CVD. If confirmed, a com- 
mon targeted therapy needs to be given for both diseases. Moreover, since patients are less likely to spontaneously come forward with hemorrhoidal symptoms, physicians should consider the above-mentioned risk factors and be proactive in diagnosing hemorrhoids if suspected. As hemorrhoidal symptoms affect patients in all grades, a conservative treatment therefore should be the cornerstone of care.

\section{Approval}

Got approval from the respective department.

\section{Authors Contributions}

SF Kabir designed and developed the study. DDas and KZ Alam collected data and prepared the manuscript, M Murshed and D Mohammad data analyzed and revised the draft and provided technical guidance. SF Kabir and DDas re-reviewed the manuscript and finalized the manuscript.

\section{Acknowledgements}

We thank Dr. Md Ariful Islam, Bagerhat Sadar Hospital, Dr. Shiladitya Shil, Dinajpur Sadar Hospital, Dr. Shaikh Adnan Rakib, Bangladesh Medical College \& Hospital, Dr. Gouranga Kumar Bose, Sheikh Hasina Medical College \& Hospital, Dr. Shakera Ahmed, Chattogram Medical College \& Hospital, Dr. Sonia Akter, Enam Medical College \& Hospital, Dr. Mohammad Arif Hossain, Cox’s Bazar Medical College \& Hospital, Dr. Gazi Muhammad Salahuddin, Faridpur Medical College \& Hospital, Dr. Sreekanta Chandra Banik, Chattogram Medical College \& Hospital, Dr. Mohammad Yunus Haroon Chowdhury, Chattogram Medical College \& Hospital, Dr. Md. Aziz Ullah, Cumilla Medical College \& Hospital, Dr. Mahmud Sultan, BIRDEM General Hospital, Dr. Md. Sadekul Alom Piash, Moulvibazar 250 Bedded Hospital, Dr. Sayera Banu Sheuly, Chattogram Medical College \& Hospital, Dr. S. K. Forhad, Victoria General Hospital for their valuable contribution to the data collection for this research.

\section{Conflicts of Interest}

The authors declare no conflicts of interest regarding the publication of this paper.

\section{References}

[1] Everhart, J.E. and Ruhl, CE. (2009) Burden of Digestive Diseases in the United States Part I: Overall and Upper Gastrointestinal Diseases. Gastroenterology, 136, 376-386. https://doi.org/10.1053/j.gastro.2008.12.015

[2] Liebach, J.R. and Cerda, J.J. (1991) Hemorrhoids: Modern Treatment Methods. Journal of Hospital Medicine, 53-68.

[3] Abramowitz, L., Benabderrahmane, M., Pospait, D., Philip, D. and Laouénan, C. (2014) The Prevalence of Proctological Symptoms amongst Patients Who See General Practitioners in France. European Journal of General Practice, 20, 301-306. 
https://doi.org/10.3109/13814788.2014.899578

[4] Tournu, G., Abramowitz, L., Couffignal, C., Juguet, F., Sénéjoux, A., Berger, S., et al. (2017) GREP Study Group; MG-PREVAPROCT Study Group. Prevalence of Anal Symptoms in General Practice: A Prospective Study. BMC Family Practice, 18, Article No. 78. https://doi.org/10.1186/s12875-017-0649-6

[5] Lohsiriwat, V. (2012) Hemorrhoids: From Basic Pathophysiology to Clinical Management. World Journal of Gastroenterology, 18, 2009-2017. https://doi.org/10.3748/wjg.v18.i17.2009

[6] Heaton, K.W., Radvan, J., Cripps, H., Mountford, R.A., Braddon, F.E. and Hughes, A.O. (1992) Defecation Frequency and Timing, and Stool Form in the General Population: A Prospective Study. Gut, 33, 818-824. https://doi.org/10.1136/gut.33.6.818

[7] Goligher, J.C. (1980) Haemorrhoids or Piles. Surgery of the Anus, Rectum and Colon, 4th Edition, Baillere Tindall, London, 93-135.

[8] Eklof, B., Rutherford, R.B., Bergan, J.J., Carpentier, P.H., Gloviczki, P., Kistner, R.L., et al. (2004) American Venous Forum International Ad Hoc Committee for Revision of the CEAP Classification-Revision of the CEAP Classification for Chronic Venous Disorders: Consensus Statement. Journal of Vascular Surgery, 40, 1248-1252.

https://doi.org/10.1016/j.jvs.2004.09.027

[9] Avsar, A.F. and Keskin, H.L. (2010) Haemorrhoids during Pregnancy. Journal of Obstetrics and Gynaecology, 30, 231-237.

https://doi.org/10.3109/01443610903439242

[10] Hollingshead, J.R. and Phillips, R.K. (2016) Haemorrhoids: Modern Diagnosis and Treatment. Postgraduate Medical Journal, 92, 4-8. https://doi.org/10.1136/postgradmedj-2015-133328

[11] Chang, S.S., Sung, F.C., Lin, C.L. and Hu, W.S. (2017) Association between Hemorrhoid and Risk of Coronary Heart Disease: A Nationwide Population-Based Cohort Study. Medicine (Baltimore), 96, Article ID: e7662. https://doi.org/10.1097/MD.0000000000007662

[12] Singh, G., Lingala, V., Wang, H., Vadhavkar, S., Kahler, K.H., Mithal, A., et al. (2007) Use of Health Care Resources and Cost of Care for Adults with Constipation. Clinical Gastroenterology and Hepatology, 5, 1053-1058. https://doi.org/10.1016/j.cgh.2007.04.019

[13] Riss, S., Weiser, F.A., Schwameis, K., Mittlböck, M. and Stift, A. (2011) Haemorrhoids, Constipation and Faecal Incontinence: Is There Any Relationship? Colorectal Disease, 13, e227-e233. https://doi.org/10.1111/j.1463-1318.2011.02632.x

[14] Peery, A.F., Sandler, R.S., Galanko, J.A., Bresalier, R.S., Figueiredo, J.C., Ahnen, D.J., et al. (2015) Risk Factors for Hemorrhoids on Screening Colonoscopy. PLoS ONE, 10, e0139100. https://doi.org/10.1371/journal.pone.0139100

[15] Sanchez, C. and Chinn, B.T. (2011) Hemorrhoids. Clinics in Colon and Rectal Surgery, 24, 5-13. https://doi.org/10.1055/s-0031-1272818

[16] MacKay, D. (2001) Hemorrhoids and Varicose Veins: A Review of Treatment Options. Alternative Medicine Review, 6, 126-140.

[17] Burkitt, D.P. (1972) Varicose Veins, Deep Vein Thrombosis, and Haemorrhoids: Epidemiology and Suggested Aetiology. The BMJ, 2, 556-561.

https://doi.org/10.1136/bmj.2.5813.556

[18] Acs, N., Bánhidy, F. and Czeizel, A.E. (Eds.) Congenital Abnormalities and Preterm Birth Related to Maternal Illnesses during Pregnancy, Chapter 10.12. Springer, Berlin, 234-237. 
[19] Higuero, T., Abramowitz, L., Castinel, A., Fathallah, N., Hemery, P., Laclotte Duhoux, C., et al. (2016) Guidelines for the Treatment of Hemorrhoids (Short Report). Journal of Visceral Surgery, 153, Article ID: 213218. https://doi.org/10.1016/j.jviscsurg.2016.03.004

[20] Davis, B.R., Lee-Kong, S.A., Migaly, J., Feingold, D.L. and Steele, S.R. (2018) The American Society of Colon and Rectal Surgeons Clinical Practice Guidelines for the Management of Hemorrhoids. Diseases of the Colon \& Rectum, 61, 284-292. https://doi.org/10.1097/DCR.0000000000001030

[21] Wald, A., Bharucha, A.E., Cosman, B.C. and Whitehead, W.E. (2014) ACG Clinical Guideline: Management of Benign Anorectal Disorders. The American Journal of Gastroenterology, 109, 1141-1157. https://doi.org/10.1038/ajg.2014.190

[22] Zagriadskiĭ, E.A. (2018) Conservative Treatment of Hemorrhoids: Results of an Observational Multicenter Atudy. Advances in Therapy, 35, 1979-1993.

https://doi.org/10.1007/s12325-018-0794-x

[23] Agarwal, N., Singh, K., Sheikh, P., Mittal, K., Mathai, V. and Kumar, A. (2017) Executive Summary-The Association of Colon \& Rectal Surgeons of India (ACRSI) Practice Guidelines for the Management of Haemorrhoids-2016. Indian Journal of Surgery, 79, 58-61. https://doi.org/10.1007/s12262-016-1578-7

[24] Katsenis, K. (2005) Micronized Purified Flavonoid Fraction (MPFF): A Review of Its Pharmacological Effects, Therapeutic Efficacy and Benefits in the Management of Chronic Venous Insufficiency. Current Vascular Pharmacology, 3, 1-9. https://doi.org/10.2174/1570161052773870

[25] Misra, M.C. and Parshad, R. (2000) Randomized Clinical Trial of Micronized Flavonoids in the Early Control of Bleeding from Acute Internal Haemorrhoids. British Journal of Surgery, 87, 868-872. https://doi.org/10.1046/j.1365-2168.2000.01448.x

[26] Nicolaides, A.N., Allegra, C., Bergan, J., Bradbury, A., Cairols, M., Carpentier, P., et al. (2008) Management of Chronic Venous Disorders of the Lower Limbs: Guidelines according to Scientific Evidence. International Angiology, 27, 1-59. https://doi.org/10.1177/000331970005100101 